\title{
ACESSO A MEDICAMENTOS: ANÁLISE DAS ESTRATÉGIAS DO ESTADO PARA O DESENVOLVIMENTO DO PROGRAMA FARMÁCIA POPULAR.
}

\author{
MEANS OF ACCESS TO MEDICINE: ANALYSING STATE STRATEGIES TO IMPROVE THE POPULAR PHARMACY PROGRAM
}

\section{RESUMO}

O artigo analisa o Programa Farmácia Popular para entender se o sistema implantado pelo governo federal atende à demanda da população e contribui para a melhora da saúde pública. Analisa-se a eficácia do Programa Farmácia Popular, que possui uma ação em rede através de parceria público-privada, e a contribuição deste Programa para a resolução de problemas de acesso a medicamentos prescritos no sistema de saúde. O principal objetivo desta análise é avaliar o desempenho do atual modelo do Programa Farmácia Popular, considerando a participação dos seus agentes frente à organização em rede. O artigo inclui uma revisão conceitual do modelo de assistência farmacêutica e uma revisão bibliográfica da sociedade em rede. Os dados analisados foram obtidos por meio de levantamento realizado junto a farmácias e drogarias credenciadas pelo Programa Farmácia Popular e em análise do banco de dados de uma empresa gestora de assistência farmacêutica.

PALAVRAS-CHAVE Programa Farmácia Popular, políticas públicas, saúde pública, assistência farmacêutica e organização em rede.

\author{
Marcos Inocencio minocencio@epharma.com.br \\ Administrador, Mestre em Administração de Empresas pela PUC-SP
}

Bruna De Vivo bvivo@epharma.com.br

Farmacêutica, Especialista em Economia e Gestão da Saúde pela PUC-SP

Artigo submetido no dia 05.04.2011 e aprovado em 05.09.2011

\begin{abstract}
This paper aims to examine the Popular Pharmacy Program to understand if the system implemented by the federal government meets the population's demand, contributing to improve public health. Defining the problem the article discusses the effectiveness of the Popular Pharmacy Program, a network which operates through a public-private partnership scheme, and the contribution of this Program to solve the problems related to the lack of access to medicines recommended by the Public Health System. The article's main goal is to evaluate the Popular Pharmacy Program performance, taking into account the model chosen, which is based on a network organization. The paper includes a conceptual review of the pharmaceutical assistance model and a literature review about the network society. The survey data analyzed were obtained from private retail pharmacies accredited for the Program and from a management company from the pharmaceutical sector.
\end{abstract}

KEYWORDS Popular Pharmacy Program, public policies, public health, pharmaceutical assistance e net organization. 


\section{INTRODUÇÃO}

Em razão de pressões de custo, qualidade e acesso, o sistema de saúde atualmente é caracterizado por uma crise mundial. Os consumidores estão exigindo serviços de saúde em maior quantidade e de melhor qualidade. No entanto, em quase todos os países do mundo, a demanda por serviços de saúde cresce bem mais rapidamente do que a disposição e a capacidade de pagar por esses serviços.

Entre os fatores que levaram o sistema de saúde à situação em que se encontra, estão as pressões financeiras, a demanda por serviços da população que envelhece, as mudanças demográicas, o consumismo, as novas e caras tecnologias de tratamentos e a maior incidência de doenças crônicas e infecciosas. Atualmente, as doenças crônicas são responsáveis por $60 \%$ das 58 milhões de mortes no mundo a cada ano (ONU, 2005). Trata-se de uma fatia que chega a $75 \%$ dos recursos destinados a saúde. (CDCP, 2003).

$\mathrm{Na}$ comparação internacional, o gasto total do Brasil com saúde foi de $7,5 \%$ do PIB, que está abaixo dos 9,7\% do PIB na média mundial (Figura 1). Mas o que de fato chama a atenção é a baixa participação pública no gasto total. Dos $48 \%$ do total do gasto público no financiamento da saúde, 3,6\% equivale ao PIB, o que não é compatível com um sistema de saúde que pretende ser universal e de atendimento integral. Nessas condições, o gasto privado é obrigado a complementar os $52 \%$ restantes do gasto total, ou seja, $3,9 \%$ do PIB, com recursos próprios. Dada a desigual distribuição da renda e a regressividade da carga tributária, a menor participação do governo penaliza fortemente as classes menos favorecidas. (INTERFARMA, 2010)

De forma consistente com os demais problemas de saúde no Brasil, há milhões de pessoas sem acesso aos medicamentos. $\mathrm{O}$ acesso aos medicamentos é um componente essencial de inclusão social e de busca da equidade e fortalecimento do sistema de saúde. Salienta-se, ainda, que o acesso aos medicamentos não pode estar desvinculado da existência de uma rede de serviços de saúde.

O gasto público com medicamentos no Brasil representa apenas $0,33 \%$ do Produto Interno Bruto, enquanto o valor médio do gasto público em países da OCDE é de $0,92 \%$ do PIB. Por conta dessa baixa participação, mais de $45 \%$ dos gastos com assistência à saúde do grupo das famí-

\section{Figura 1 - Gastos totais com saúde dos países em termos de porcentagem do PIB}

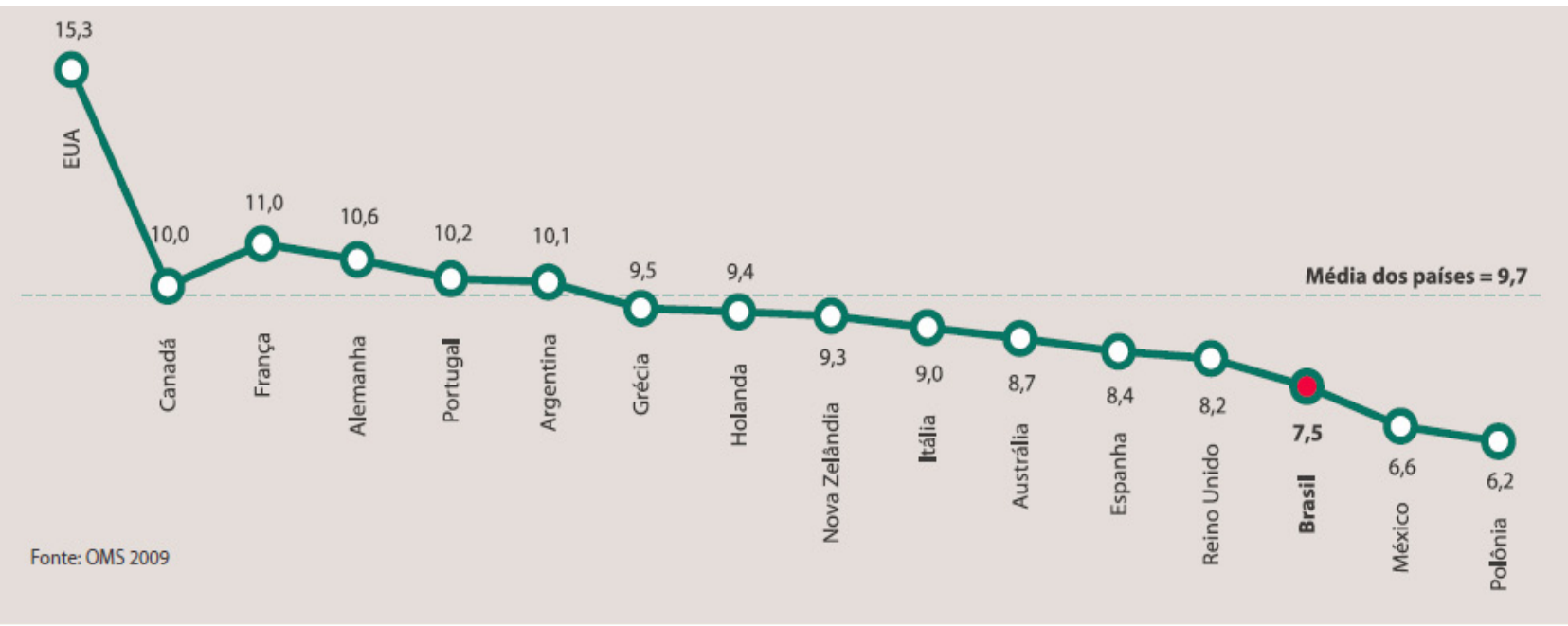

Fonte: OMS 2009 
lias 40\% mais pobres é gasto com medicamentos (OECD, 2009).

O medicamento é um dos componentes fundamentais, entre outros, pelo seu poder preventivo e terapêutico. Promover o acesso da população a medicamentos é uma das formas de atender a um preceito constitucional de promoção, proteção e recuperação da saúde.

Em 2008, o gasto federal com aquisição de remédios foi de $\mathrm{R} \$ 5,86$ bilhões e a variação para 2009 foi pequena e alcançou R \$ 5,89 bilhões. No ano passado, 460 tipos de medicamentos foram ofertados gratuitamente à população pelo Sistema Único de Saúde - SUS. Do total, o Ministério da Saúde centralizou a compra de 89 e repassou aos Estados R\$ 2,7 bilhões para a aquisição dos outros remédios. Contudo, dividindo os valores pelo número de habitantes, a despesa caiu, dado o crescimento da população no mesmo período. Ela foi de $\mathrm{R} \$ 30,93$ per capita, em 2008, e de $\mathrm{R} \$$ 30,70, no ano seguinte, é o que mostram dados do Instituto Brasileiro de Geografia e Estatística IBGE (IBGE, 2009).

O fato é que os impactos da falta de uma política eficiente de assistência à saúde e farmacêutica vão além dos custos com consulta médica, tratamentos, internação ou medicamentos. É preciso contabilizar fatores indiretos como dias perdidos de trabalho e até mesmo aposentadoria precoce.

Neste contexto, a questão central deste artigo é analisar o Programa Farmácia Popular para entender se o sistema implantado pelo governo federal atende à demanda da população e contribui para melhor acesso aos medicamentos prescritos assim como a sua composição no sistema de saúde. O objetivo principal desta pesquisa é avaliar o desempenho do atual modelo deste Programa, considerando a pareceria público-privada adotada pelo Estado como um modelo suficiente e competente a atingir os objetivos sociais em questão, que é o bem-estar da população, neste caso, contribuindo através do acesso aos medicamen- tos prescritos. No cenário descrito, a parceria público-privada tem o objetivo específico de ser analisada e fundamentada considerando a participação dos seus agentes incluídos e organizados em uma sociedade em rede.

\section{A SOCIEDADE EM REDE}

O reconhecimento de que nenhuma organização pública ou privada contempla em si mesma todos os recursos e competências necessárias a uma oferta compatível com a demanda é um fator que remete as organizações a ações articuladas de complementaridade. De um lado, essa arquitetura é expressa por um banco de oferta de recursos e competências disponibilizados formal e informalmente por instituições, organizações ou pessoas; de outro, por um banco de demandas sociais e dos próprios componentes da rede.

Tomada sob o ponto de vista organizacional, remete ainda a outros fatores que influenciam a formação de redes: a maximização e a "facilitação" dos processos produtivos; a possibilidade de incorporar "oxigenadores" do ambiente que evitam a asfixia e a entropia nas organizações, trazendo "diversidade genética"; possibilidade de inovação pela amplificação da troca de informações.

De acordo com Dabas (1995, p.452), no emergente movimento social, as redes podem abrir caminho para a requerida intervenção social. Assim, relatam que "muitos desses processos podem ser avaliados criticamente e novas formas de relações podem ser propostas a fim de contemplar não a inclusão de uns e de outros, mas a participação ativa de todos os atores envolvidos em uma dada situação, pensados então como rede".

Sob o ponto de vista social, como aponta Saidón (1995, p.205), é possível também analisar a rede social como uma organização comunitária, em que não se deve apenas proteger-se contra os 


\section{MARCOS INOCENCIO E BRUNA DE VIVO}

riscos do presente, mas sim "criar as condições para enfrentá-los, e a rede é um dos planos de consistência que nos permitem uma construção nesse sentido". E Inojosa (1998, p. 7-8) salienta que "a rede tende a ser constituída como um recurso capaz de suprir interesses e reivindicação de demanda e são parcerias para a realização de um interesse comum com o objetivo primário de formação de uma sociedade solidária".

$\mathrm{Na}$ esfera econômica a rede constitui a estratégia na busca de minimizar custos de capital, conseguir competências tecnológicas, compartilhar recursos e informações e estabelecer parcerias agregadoras. Pode-se dizer que a constituição de redes é a única resposta aos desafios enfrentados pelas organizações públicas e privadas em um mercado de intensa competição trazida pela globalização da economia.

O modelo que opta por atuar isoladamente, no lugar de constituir uma forma inter-relacionada, está perdendo espaço, por possuir menores possibilidades de êxito. A complexidade em que o ambiente nos insere, somadas as inerentes exposições às incertezas cada vez maiores, traz a exigência de parcerias consolidadas estrategicamente constituídas. Assim, a formação de parcerias, através de redes, torna-se necessária para alcançar objetivos estratégicos de longo prazo, que de forma isolada, não podem ser alcançadas.

Essas parcerias em rede, que também poderiam ser chamadas de união de competências, capacitam todos os seus integrantes na obtenção de vantagens estratégicas essenciais ao sucesso. $\mathrm{Na}$ verdade, as estruturas de rede devem ocorrer quando trabalhar isoladamente já não é suficiente o bastante para solucionar um problema ou questão de política. Assim, uma estrutura de rede se forma quando as organizações percebem que são apenas uma pequena parte do quadro completo. Nesse sentido, por meio de um trabalho de forma ativa e pelo desempenho conjunto e amplo, é possível atingir os objetivos comuns de interesse
(KEAST et al., 2004).

Conforme Inojosa (1998, p. 18), rede é parceria voluntária para a realização de um propósito comum. Implica, nesse sentido, a existência de entes autônomos que, movidos por uma ideia abraçada coletivamente, livremente e mantendo sua própria identidade, articulam-se para realizar objetivos comuns. Desse modo, salienta que "as redes se tecem através do compartilhamento de interpretações e sentidos e da realização de ações articuladas pelos parceiros". Um dos objetivos associados deste enfoque é o entendimento de processo e fatores que contribuem para uma eficiência coletiva, considerando mais fácil de ser alcançada do que isoladamente, e que pode promover o aumento da capacidade competitiva das firmas integrantes de uma rede.

$\mathrm{Na}$ literatura, é possível encontrar várias definições de rede:

De acordo com Castells (2007, p.566), "redes são estruturas abertas capazes de expandir de forma ilimitada, integrando novos nós desde que consigam comunicar-se dentro da rede, ou seja, desde que compartilhem os mesmos códigos de comunicação".

Para Najmanovich (1995, p. 71):

\begin{abstract}
A metáfora da rede, especialmente a dos fluxos variáveis com deslocamento dos pontos de encontro e renovação das pautas de conexão, tem se mostrado especialmente apta para pensar e construir novas formas de convivência que permitam forjar novos mundos em que sejamos co-protagonistas, que evoluem conjuntamente graças a permanente integração entre encontro e diferença.
\end{abstract}

Por sua vez, Souz e Quandt (2008, p. 34) afirmam que "redes sociais são estruturas dinâmicas e complexas formadas por pessoas com valores e/ou objetivos em comum, interligadas de forma horizontal e predominantemente descentralizada".

Agranoff e McGuire (2001) salientam que: 
O termo redes, tal como empregado na literatura, se refere tipicamente a arranjos multiorganizacionais voltados para a resolução de problemas que não podem ser sanados, ao menos não facilmente, por organizações isoladas. As redes de gestão pública são lideradas ou geridas por representantes governamentais. Posto de forma simples, as redes são um fenômeno emergente que consiste em veículos distintos de gestão e que oferece desafios para as organizações isoladas e seu processo de gestão.

$\mathrm{Na}$ visão de O`Toole (1997), as redes exigem certa estabilidade estrutural, mas se estendem além dos vínculos formalmente estabelecidos e das ligações legítimas de políticas públicas. A noção de redes exclui meras hierarquias formais e mercados perfeitos, mas inclui um amplo conjunto de estruturas. O vínculo institucional que sustenta as relações em rede pode incluir cadeias de autoridade, relações de troca e coalizões baseadas em interesses comuns, todas fazendo parte de uma estrutura policêntrica singular.

Segundo Fleury e Ouverney (2007), através de redes de cooperação, todos envolvidos teriam a possibilidade de superar suas dificuldades e potencializar suas vantagens, dispondo-se a colaborar umas com as outras, porque esperam, conjuntamente, realizar ações que levem a desempenhos superiores e sejam inviáveis individualmente. Nesses termos, afirma-se que a definição dos objetivos da rede é um momento de vital importância a todo o processo de sua construção e gestão.

A construção de uma rede envolve a existência de um objetivo maior, que se torne um valor compartilhado para além dos objetivos particulares que permanecem. A capacidade para estabelecer esse objetivo maior, implicando uma linha básica de acordo, relaciona-se ao grau de compatibilidade e congruência de valores entre os membros da rede. Assim, afirmam Fleury e Ouverney (2007) que "o apoio a uma política que favoreça os objetivos de vários atores é uma estratégia da gerência das redes, assim como a ativação seletiva por meio de incentivos para desenvolver arranjos organizacionais (coalizão) e interações entre os membros." (p. 28).

Como apontam Castells (2007) e Touraine (1959), o ponto central na formação de redes para a busca dos objetivos comuns é que as estratégias de formação de redes dotam o sistema de flexibilidade, mas não resolvem o problema da adaptabilidade dos atores sociais. Para conseguir absorver os benefícios da flexibilidade das redes, o próprio ator social deve tornar-se uma rede e dinamizar cada elemento de sua estrutura interna.

Para os autores, transformar a organização em uma rede articulada de centros multifuncionais de processos decisórios passa a ser essencial para se evitar erros de articulação, que neste caso, retrata a falta parcial ou total de adequação entre o que é desejado e o que está disponível. O modelo de produção flexível, em suas formas diferentes, maximiza a resposta dos agentes e as unidades econômicas a um ambiente em rápido crescimento.

Atualmente, a ligação em rede é a forma mais eficiente de organizar o tempo, a energia, os recursos e as decisões de colaboração a favor de qualquer causa. Isso significa que a complexidade de estruturas explicativas não depende apenas do número de fatores e elementos envolvidos, mas também da integridade, diversidade e interatividade das conexões nos processos dinâmicos que compõem as redes. $\mathrm{Na}$ análise das redes sociais, a efetividade de um atuante só pode ser quantificada em termos de fluxo de mensagens e conectividade.

Para alguns, mais do que uma nova perspectiva analítica, as redes representam uma mudança na estrutura política da sociedade, ou seja, novas formas de organização social em resposta aos problemas políticos de coordenação ou medida social.

As redes tendem a criar processos decisórios 
caracterizados por maior nível de democratização, uma vez que operam por meio da produção de consenso entre os participantes, sendo a circulação de informação o recurso estratégico nas decisões. Nesse contexto, os elementos essenciais à caracterização de uma estrutura em rede é a existência de ações estrategicamente planejadas, uma missão comum, o compromisso com metas acordadas coletivamente e o intercâmbio constante e duradouro de recursos.

Ademais, a importância estratégica da formação de uma rede ocorre pelo estabelecimento de acordos de cooperação, reciprocidade e alianças, visando a encontrar saídas para intervir na realidade complexa. A rede não é apenas um objetivo em si, mas parte de uma metodologia para a ação, que permita manter, ampliar ou criar alternativas desejáveis.

$\mathrm{Na}$ visão de Junqueira (2000), o processo de redes, ao articular os diversos atores sociais, possibilita superar a incapacidade dos responsáveis pela gestão. Não se trata somente da construção de uma realidade de vínculos, mas também de uma maneira de analisar e entender a realidade.

O modelo de gestão em rede, para Fleury e Ouverney (2007), estende o foco analítico para as relações intersetoriais. Todavia, nesse caso, a liderança é colaborativa. Os atores no sistema dependem uns dos outros, porque precisam dos recursos alheios para atingir suas metas e objetivos.

A interdependência significa que todos os atores devem se beneficiar de alguma forma, em virtude de seu interesse comum em uma atividade específica, e que o problema particular só pode ser sanado se os atores envolvidos buscarem suas soluções de forma estratégica e colaborativa (KEAST et al., 2004). Nesse sentido, Fleury e Ouverney (op.cit, p.7) complementam que "apesar da diversidade de contextos institucionais, impõe-se esta nova realidade caracterizada pela dependência mutua, visto que nenhum ator detém o controle dos recursos e do processo total".
A organização em rede fornece aos seus integrantes um instrumento fundamental para a gerência das políticas em contextos democráticos, permitindo a construção de novas formas de coletivização, socialização, organizações solidárias e coordenação. As redes de políticas podem ser tomadas como uma tentativa de criar novas formas de coordenação, capazes de atender às necessidades e características do contexto atual, em que o poder se apresenta como plural e diversificado. Assim, Junqueira (2000) relata que as redes sociais se expressam como um conjunto de pessoas e organizações que se relacionam para responder demandas e necessidades da população de maneira integrada, mas respeitando o saber e a autonomia de cada membro.

Como ponto estratégico, para Castells (2007), é ainda possível destacar que constituem redes produtivas e de gerenciamento as estruturas cujas flexibilidades não precisam incorporar todos os atores, mas que devem ser capaz de acessá-los quando for conveniente e quantas vezes forem necessárias em cada situação específica. Contudo, dentre essas situações específicas, Souza (2005, p.49) salienta que "a capacidade de integrar conhecimento e transformar competências tácitas e explícitas em um corpo de conhecimento organizacional dependeria da habilidade de interagir e compartilhar conhecimento".

\section{O PROGRAMA FARMÁCIA POPULAR}

O Governo Federal criou através da Lei 10.858 de 13 de abril de 2004, que foi regulamentada pelo Decreto $\mathrm{n}^{\circ} 5.090$ de maio de 2004, o Programa Farmácia Popular do Brasil para ampliar o acesso aos medicamentos para as doenças mais comuns entre os cidadãos. O principal intuito deste Programa é prover assistência farmacêutica à população, sendo que o Ministério da Saúde 
através da Política Nacional de Medicamentos definiu a Assistência Farmacêutica como um "grupo de atividades relacionadas com o medicamento, destinadas a apoiar as ações de saúde demandadas por uma comunidade" (BRASIL, 2001). Um dos objetivos do Programa é favorecer as pessoas de baixa renda, viabilizar a realização do tratamento em face ao alto preço dos medicamentos e ainda suportar a população usuária da rede privada de saúde como uma alternativa, já que passaram a ter acesso a medicamentos com preços mais acessíveis. Outro fator importante é que o Programa Farmácia Popular pode contribuir para a diminuição dos gastos gerados pela compra de medicamentos e, também minimizar as despesas do Sistema Único de Saúde com internações que são provocadas pelo abandono do tratamento.

O Programa possui uma rede própria de Farmácias Populares e a parceria com farmácias e drogarias da rede privada, chamada de Aqui tem Farmácia Popular. A análise desenvolvida neste artigo considerou somete o Aqui tem Farmácia Popular, uma vez que somente este modelo trata os seus agentes como atores sociais organizados em rede.

O delineamento desta pesquisa possibilitou colocar o problema em termos de verificação empírica, sendo o delineamento neste contexto, o planejamento da pesquisa em sua dimensão mais ampla, envolvendo a interpretação dos dados. O elemento mais importante para a identificação deste delineamento foi o procedimento adotado para a captação de dados. O procedimento adotado nesta pesquisa foi o estudo de caso.

A partir da revisão bibliográfica da organização em rede, dos dados primários captados nas farmácias credenciadas ao Programa Farmácia Popular e ainda dos dados reais do mercado privado obtidos de uma organização de gestão de assistência farmacêutica que captura dados de vendas nas farmácias privadas em todo o território nacional, buscamos constatar a eficácia da assistência farmacêutica através deste Programa para entender a proposta de sua contribuição ao sistema de saúde através de uma rede integrada com ganhos em todas as dimensões desse ambiente.

A abrangência da pesquisa tomou as informações relativas ao Programa Aqui tem Farmácia Popular, compreendidas entre o período de janeiro à dezembro de 2010, relativo aos movimentos de vendas de 1.536 pontos de venda, ou farmácias, em 26 Estados mais o Distrito Federal, abrangendo as informações de 1.946 .834 vendas, que movimentaram $\mathrm{R} \$ 51.939$ mil e 4.570 .942 unidades dispensadas.

De modo geral, as informações analisadas mostraram que o início do exercício de 2010 movimentou 575.814 unidades dispensadas em janeiro e, no decorrer do ano, houve uma redução considerável de $45 \%$ em unidades vendidas demonstrando em dezembro a dispensação de 315.371 unidades com uma redução de $49,5 \%$ quando comparado ao mesmo período de 2009. Das autorizações de vendas solicitadas pelas farmácias ao DATASUS, 17,6\% foram recusadas, sendo que daquelas autorizadas, $91,0 \%$ foram efetivamente dispensadas, o que monta um resultado de unidades efetivamente dispensadas de $72,6 \%$ sobre o total solicitado. $\mathrm{O}$ acesso da população ao Programa, que em dezembro de 2010 abrangeu 151.973 beneficiários contados de forma não distinta (32\% menor quando comparado aos 224.452 no início do exercício em janeiro/2010 e 37\% menor quando comparado a dezembro/2009) atingiu no ano de 20101.946 .834 beneficiados, sendo que apenas $6,9 \%$ não tiveram a sua solicitação atendida pelo Programa. Em média, foram dispensadas 3,4 unidades/beneficiário com um ticket médio de $R \$ 27,43$, constituído por medicamentos com preço médio em $\mathrm{R} \$ 10,89$. O Programa teve como subsídio médio efetivo $71,4 \%$ dos custos totais das compras dos beneficiários, subsídio esse aplicado sobre um preço de venda que já considera um desconto médio ofertado pelas farmácias na 
ordem de $28,9 \%$. O subsídio médio efetivo de $71,4 \%$ ficou abaixo do subsídio nominal de $90 \%$, previsto nas regras do Programa devido às dispensações serem feitas, em geral, com preços superiores ao preço de referência estabelecido pelo Ministério da Saúde. Dentro de um contexto geral, de janeiro à dezembro de 2010 manteve - se a queda na utilização do Programa pela população, possivelmente, devido às alterações das regras do Programa, promovidas em 2009 pelo Ministério da Saúde que passou a exigir das farmácias credenciadas um cópia das prescrições apresentadas pelos beneficiários.

Conforme dados do Ministério da Saúde (BRA-
SIL, 2010), o Programa Farmácia Popular abrange todos os estados brasileiros, presente em 2.467 municípios através de 14.005 farmácias e drogarias conveniadas, que movimentaram até dezembro de 2010 o montante total de $\mathrm{R} \$ 245.191 \mathrm{mil}$. Quando comparado ao ano de 2009 o cenário em 2010 demonstra leve queda de 13,8\% no consumo, entretanto expandiu na abrangência de farmácias conveniadas que do início do programa até dezembro de 2010 evoluiu em 36,1\% além do crescimento representativo em número de municípios atendidos que evoluiu mais de $84,1 \%$ (Figura 2).

A participação desta pesquisa no Programa

Figura 2 - Evolução do Programa Aqui tem Farmácia Popular em 2010

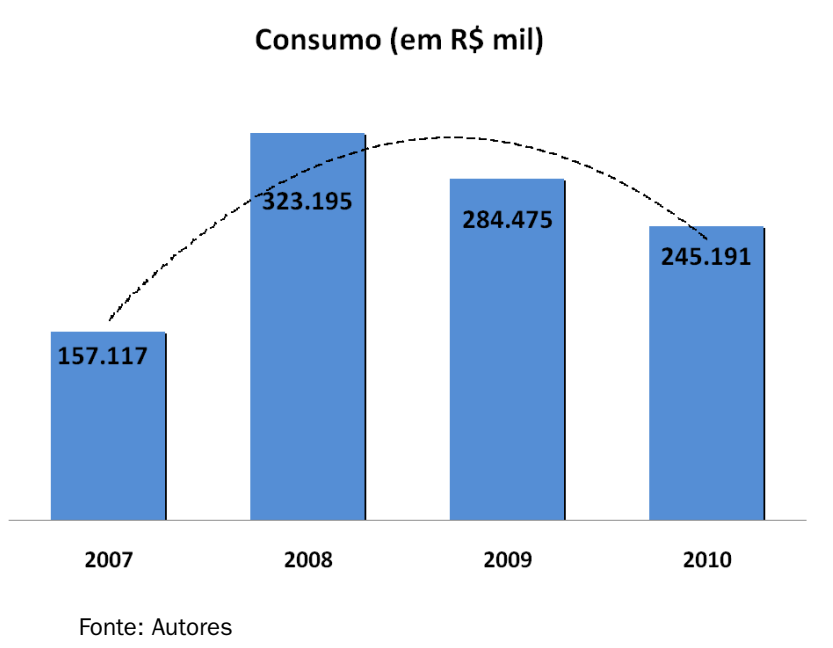

Aqui tem Farmácia Popular é bastante expressiva. A amostra abrangeu $13,3 \%$ dos municípios atendidos e 11,0\% das farmácias conveniadas.

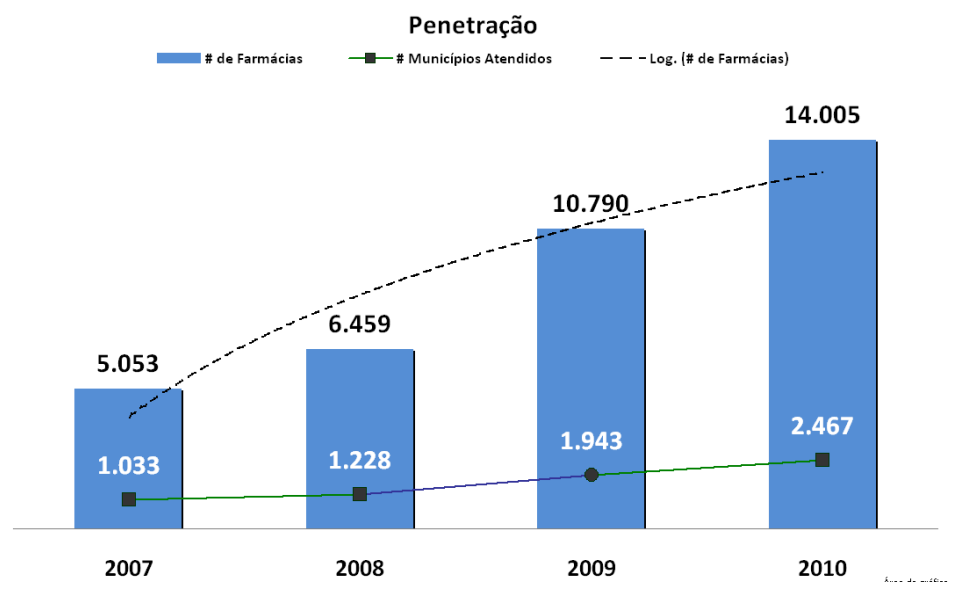

Considerando o consumo do Programa a amostra analisada é ainda mais relevante, chegou a 21,2\% do volume total do Programa (Figura 3). 
Figura 3 - Amostra: Abrangência da pesquisa

\begin{tabular}{l|c|c|c}
\multicolumn{4}{|c}{ ABRANGÊNCIA DA PESQUISA } \\
\hline DESCRIÇÃO & PESQUISA & BRASIL & \% PARTICIPAÇÃO \\
\hline \# Municípios Atendidos & 329 & 2.467 & $13,3 \%$ \\
\hline \# de Farmácias & 1.536 & 14.005 & $11,0 \%$ \\
\hline \$ Consumo & 51.939 & 245.191 & $21,2 \%$ \\
\hline
\end{tabular}

Fonte: Autores

\section{RESULTADOS DAS ANÁLISES E DISCUSSÕES}

\subsection{COBERTURA SOBRE AS DOENÇAS CRÔNICAS EA NECESSIDADE DE EXPANSÃO}

Um dos fatores relevantes que tem causado impacto no cenário atual da saúde é a mudança demográfica, trazendo ao sistema de saúde a necessidade da reavaliação de recursos e prioridades. A principal mudança nesse contexto é o envelhecimento da população mundial. Em 2005, pessoas com 60 anos ou mais já representavam uma parcela maior da população mundial $(10,4 \%)$ do que crianças com 4 anos ou menos (9,5\%) (COHEN, 2005). Essa alteração demográfica acaba refletindo uma crescente demanda por serviços de saúde e, consequentemente, aumenta os custos associados ao envelhecimento.

Outra mudança demográfica de impacto que afeta o perfil geral da saúde do planeta é o alarmante aumento de pessoas com sobrepeso, trazendo os riscos envolvidos de doenças associadas. Institutos de pesquisa estimam que, atualmente, há mais pessoas acima do peso ideal do que abaixo do peso.
Sobre isso, a OMS afirma que:

[...] em todo o mundo, estima-se que, em 2005, mais de 1 bilhão de pessoas apresentavam sobrepeso, incluindo 805 milhões de mulheres, e que mais de 300 milhões de pessoas eram obesas. Se a tendência atual continuar, projeta-se que os níveis médios de índice de massa corporal aumentarão em quase todos os países. Ate 2015, estima-se que mais de 1,5 bilhão de pessoas apresentarão sobrepeso (ONU, 2005).

Como consequência dessas alterações demográficas, um dos mais significativos promotores de mudança no sistema de saúde é a crescente incidência e o impacto causado pelas doenças crônicas, que são aquelas permanentes ou que podem exigir longos períodos de supervisão, observação ou cuidados. Seguido pelas doenças complexas, aquelas de apresentam origens multifatoriais. Atualmente, essas respondem por $60 \%$ das 58 milhões de mortes no mundo a cada ano, representando um considerável fardo econômico para as sociedades (ONU, 2005). Trata-se de uma fatia que chega a mais de $50 \%$ dos recursos destinados a saúde em países desenvolvidos, consumida pelas necessidades de doentes crônicos (Figura 4). 
Figura 4 - Impactos dos casos de doenças crônicas

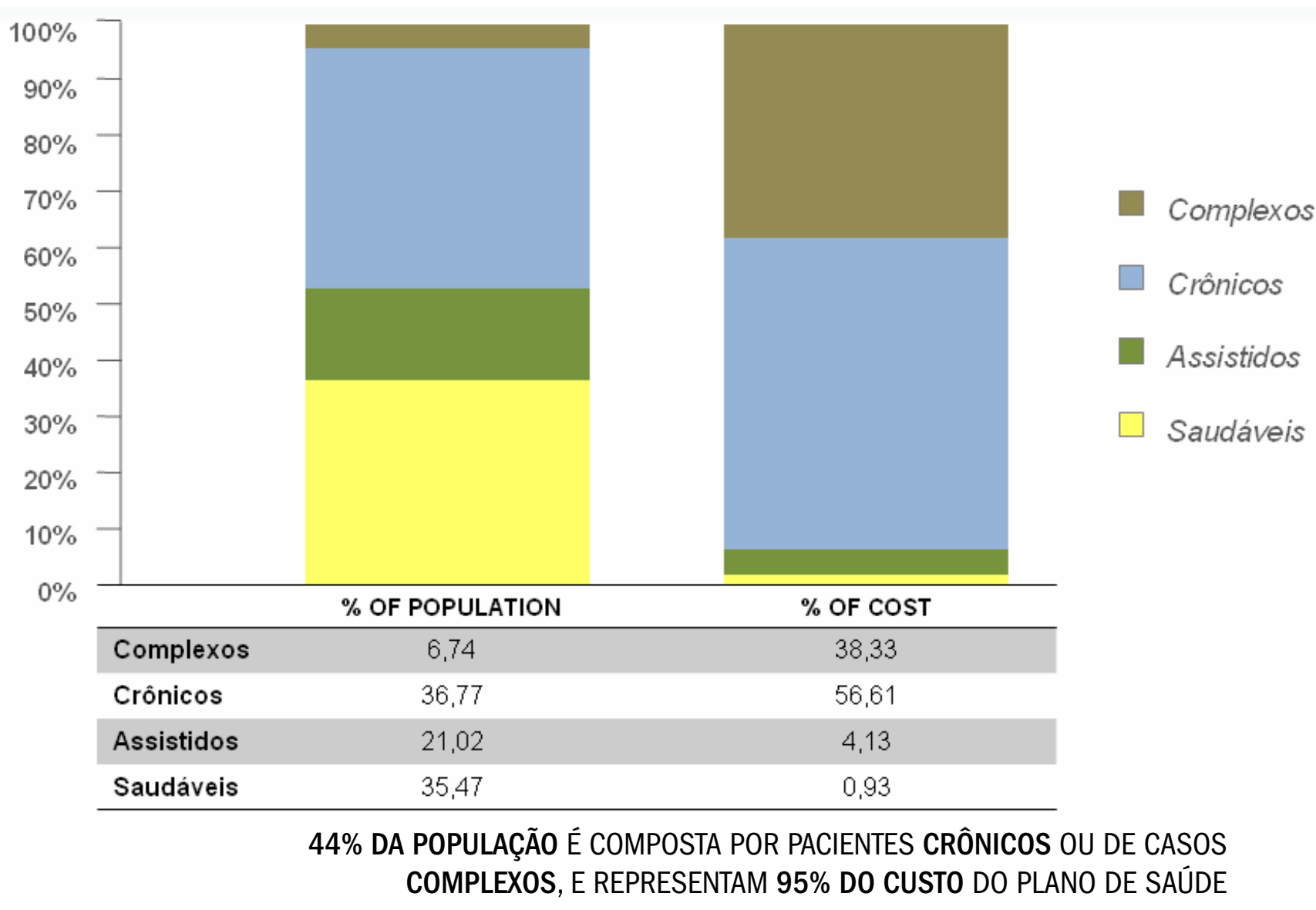

Fonte: PBMI Conference 2010

Além das doenças crônicas serem responsáveis por uma porcentagem crescente do total de mortes em países desenvolvidos, sua incidência em países em desenvolvimento e menos desenvolvidos também está em ascensão. Ademais, as chamadas "doenças de risco" são, na verdade, predominantes entre pessoas de renda baixa e média, entre as quais $80 \%$ das mortes se devem as doen- ças crônicas. Em todos os quadrantes, as populações mais pobres - aquelas mais expostas a riscos e com menos acesso a serviços de saúde - são as mais afetadas (Figura 5). Nos próximos 10 anos, estima-se que a incidência global de doenças crônicas crescerá em 17\%, aumentando ainda mais o fardo global da doença (ONU, 2005): 


\section{Figura 5 - Projeção para 2015 das principais causas de morte}

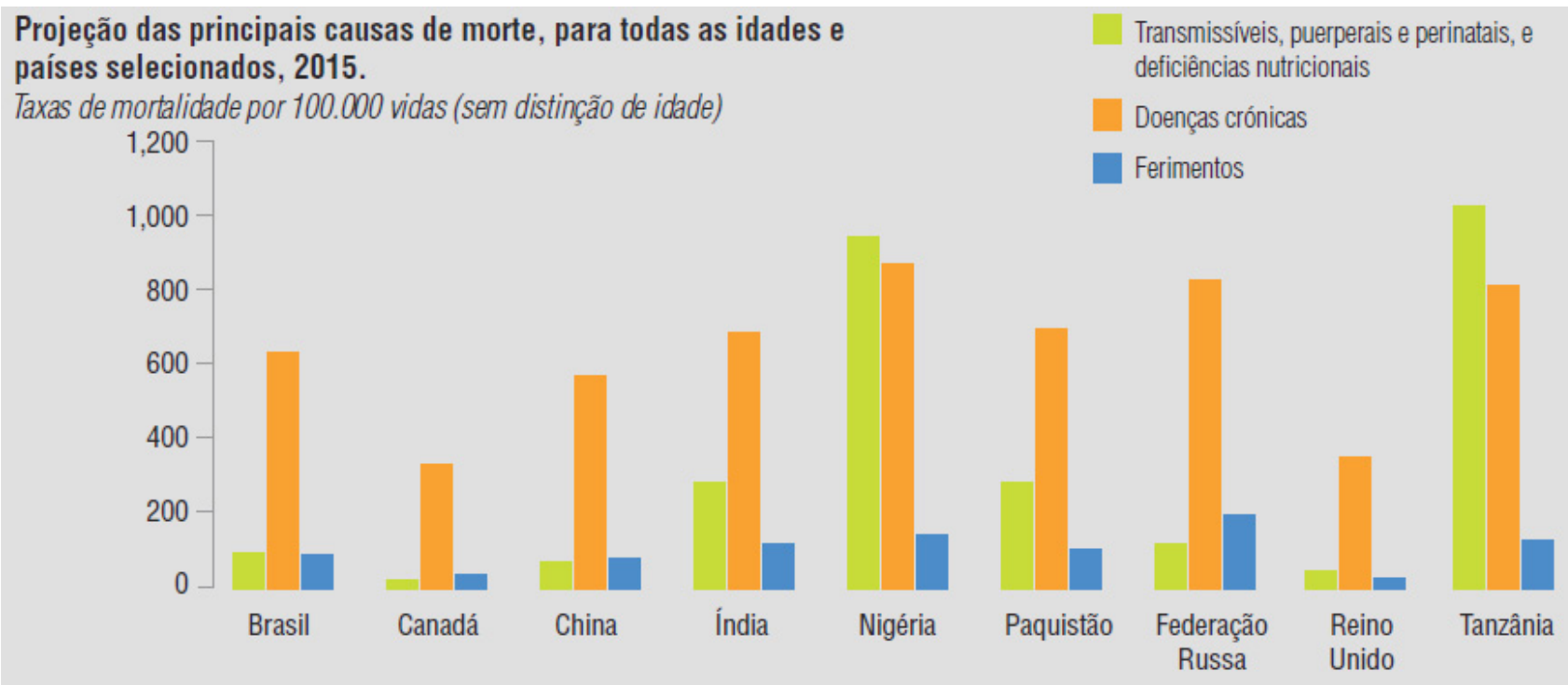

Fonte: Organização Mundial da Saúde. 2005. Preventing chronic disease: a vital investment. Genebra.

Fonte: Organização Mundial da Saúde (2005)

Da mesma forma, constatam-se alterações demográficas na população brasileira no que se refere ao envelhecimento da população, trazendo maiores demandas ao sistema de saúde e a necessidade da reavaliação da destinação dos recursos, em especial para o tratamento de doenças crônicas. Em 2004, os idosos já representavam 9,0\% da população total e correspondiam a 58,4\% da mortalidade do país (OPAS, 2007).

Em menos de 40 anos, o Brasil passou de um perfil de mortalidade típico de uma população jovem para um desenho caracterizado por enfermidades complexas e mais onerosas, próprias das faixas etárias mais avançadas. $\mathrm{O}$ fato marcante em relação às doenças crônicas é que crescem de forma muito expressiva com o passar dos anos: entre os de idade de 0 a 14 anos, foram reportados apenas 9,3\% de doenças crônicas, mas entre os idosos, esse valor atinge $75,5 \%$ (69,3\% entre os homens e 80,2\% entre as mulheres) (IBGE, 2009).

O Programa Aqui tem Farmácia Popular contempla cobertura somente a três patologias crônicas: Hipertensão, Diabetes e Dislipidemia ou colesterol, deixando fora do contexto o tratamento de algumas doenças crônicas relevantes, como obesidade e doenças respiratórias, por exemplo. A não cobertura de 100\% das doenças crônicas é um fator negativo no Programa, haja vista que este, foca contribuir para a diminuição dos gastos gerados pela compra de medicamentos e, também minimizar as despesas do Sistema Único de Saúde com internações que são provocadas pelo abandono do tratamento. Em Outubro de 2010, o programa passou a atender também a medicamentos para tratamento de: Osteoporose, Rinite, Asma, Glaucoma, Doença de Parkinson, Fraldas geriátricas e Oseltamivir para tratamento da Influenza H1N1. É uma expansão importante, mas não considera abranger à totalidade das doenças crônicas, exceto pela inclusão de medicamentos voltados ao tratamento de asma, que é parte importante no tratamento de doenças crônicas respiratórias 


\subsection{MEDICAMENTOS GENÉRICOS E SUA IMPORTÂNCIA NO PROGRAMA}

O Programa Aqui tem Farmácia Popular demonstra uma forte concentração na dispensação de medicamentos genéricos, que através da Lei 9.787, de 10 de Fevereiro de 1999, a ANVISA os define como medicamentos similares a um produto de referência ou inovador, geralmente produzido após a expiração ou renúncia da proteção patentária, comprovada a sua eficácia, segurança e qualidade. Em 2010 os genéricos corresponderam a 58,3\% do total dos medicamentos dispensados, seguido pela participação de $28,8 \%$ dos medicamentos de marca similares, que a mesma Lei 9.787 os definem como aqueles que contêm o mesmo princípio ativo e apresentam a mesma concentração, forma farmacêutica, via de administração, posologia e indicação terapêutica, preventiva ou diagnóstica, do medicamento de referência registrado no órgão federal responsável pela vigilância sanitária. Os medicamentos denominados de referência, produtos inovadores registrados no órgão federal responsável pela vigilância sanitária cuja eficácia, segurança e qualidade foram comprovadas cientificamente junto ao órgão federal competente, por ocasião do registro (inciso XXII, artigo 3º da Lei n. 6.360, de 1976) representaram 12,9\% das dispensações, seguidos por 0,02\% por não medicamentos. Quando comparado aos números do mercado, vemos uma participação dos medicamentos genéricos bastante expressiva, já que segundo o mercado brasileiro a participação dos medicamentos genéricos é de apenas 21,63\% (PROGENERICOS, 2010). Há uma queda acentuada, em valores absolutos, no consumo de medicamentos de referência e genéricos, quando comparados ao início do exercício, que apresentam as seguintes participações: Medicamentos de referência queda de 53\%, seguida pelos genéricos que apresentam uma queda expressiva de $63 \%$ e em contrapartida visualizamos aumento de 16\% no consumo de medicamentos similares. As quedas acentuadas nos medicamentos genéricos e de referencia foram, basicamente, causadas pelo redução do consumo no Programa como um todo, sendo que os medicamentos similares mantiveram a sua participação sustentas na prática de preços baixos promovidas pela indústria farmacêutica no período analisado. Embora os medicamentos genérico possuem, historicamente, o preço em média 40\% menor que os medicamentos de referencia, esta condição não foi suficiente para combater os similares, que através dos preços tiveram o seu acesso a população favorecidos. A evolução do consumo em unidades dispensadas no exercício de 2010 pode ser visualizada na Figura 6.

Considerando o foco do Programa no aumento do acesso da população, principalmente entre as classes com renda mais baixas, e na redução dos gastos com saúde do Estado, a concentração no consumo de medicamentos genéricos é bastante positiva pelo fato de que estes medicamentos possuem preços abaixo daqueles praticados pelos medicamentos de referência. Da mesma forma, os medicamentos similares também possuem preços mais acessíveis quando comparados aos medicamentos de referência. Tais concentrações trazem ao Programa resultados positivos quando consideramos o aumento do acesso aos medicamentos prescritos devido a custos mais baixos e também redução nos gastos do Estado com medicamentos pelo mesmo motivo.

\subsection{ANÁLISE DAS CLASSES TERAPÊUTICAS E PRINCÍPIOS ATIVOS CONTEMPLADOS NO PROGRAMA}

O Programa Aqui tem Farmácia Popular, que atendia a três classes terapêuticas em 2009, Hipertensão, diabetes e anticoncepcionais, passa a abranger nove classes terapêuticas a partir de outubro de 2010, incluindo produtos para os 
Figura 6 - Evolução da participação das classificações comerciais em unidades dispensadas

Unidades Dispensadas - Classificação Comercial

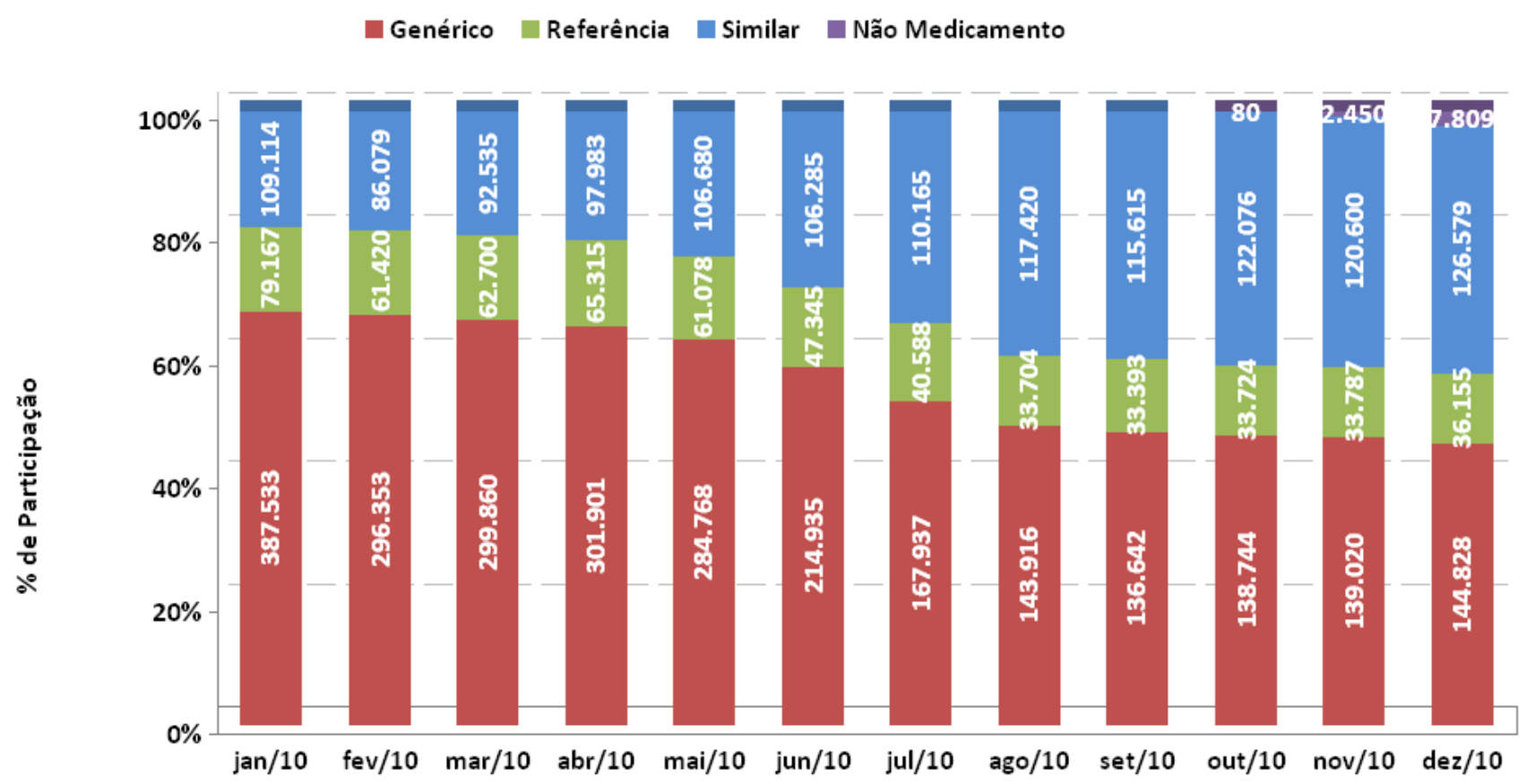

Fonte: Autores

seguintes tratamentos: Influenza $\mathrm{H} 1 \mathrm{Nl}$, Rinite e Asma, Glaucoma, Osteoporose, Doença de Parkinson e Fraldas Geriátricas. O volume de medicamentos dispensados através do Programa tem destaque nos medicamentos para tratamento de doenças do sistema cardiovascular (hipertensão), que abrange 67,0\% do volume total das dispensações; já para as dispensações dentro da classe terapêutica para tratamentos do aparelho digestivo e metabolismo (diabetes), a participação é de 23,7\% do total; e para o sistema geniturinário/ hormônios sexuais (anticoncepcionais), a participação é a menos expressiva com apenas 2,6\%. Estas três classes terapêuticas possuem maior participação no Programa devido estarem contempladas no Programa desde a sua constituição, sendo que as demais classes terapêuticas incluídas no final do exercício possuem participações discretas. Participação de 5,4\% das fraldas geriátricas, produtos para tratamento de asma/ rinite com $0,7 \%$, osteoporose com $0,4 \%$, doença de $\mathrm{Pa}$ rkinson, Glaucoma e Influenza H1N1 com 0,01\% de participação no ano de 2010 (Figura 7).

Se tomarmos os dados pelos princípios ativos, estes refletem que dos 27 princípios ativos atendidos pelo Programa Aqui tem Farmácia Popular, 5 deles concentram 80,0\% do total das dispensações, a saber: Enalapril 27,6\% (tratamento para hipertensão); Metformina 20, 2\% (tratamento de diabetes); Atenolol 16,6\% (tratamento para hipertensão); Captopril 9,1\% (tratamento para hipertensão) e Sinvastatina 9,1\% (tratamento para dislipidemias). Entre estes princípios há prevalência de medicamentos genéricos, fazendo destes medicamentos o destaque do Programa. Há princípios ativos onde prevalecem medicamentos de referência, como Estradiol, Medroxiprogesterona e Norestisterona (ambos anticoncepcionais), porém possui participação pouco expressiva no Programa. Os princípios ativos de maior relevância 
Figura 7 - Participação das classes terapêuticas no Programa Aqui tem Farmácia Popular

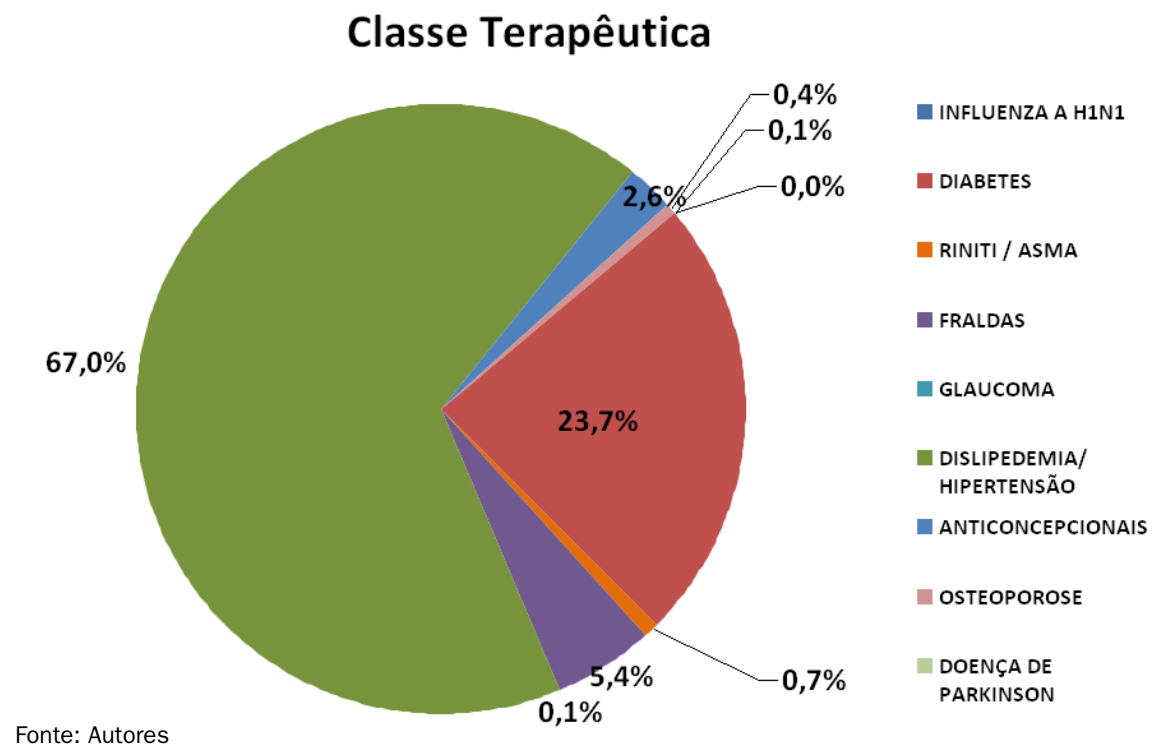

possuem preços médios mais baixos favorecendo, assim, custos menores. Os princípios ativos destinados a hipertensão são dispensados, em média, abaixo do preço de referência estabelecido.

Com o objetivo de avaliarmos os princípio ativos e os respectivos medicamentos disponíveis para a população através do Programa Aqui tem Farmácia Popular, comparamos os mesmos com aqueles mais prescritos e dispensados no mercado brasileiro. Para esta comparação obtivemos junto a ePharma, empresa privada gestora de as- sistência farmacêutica, informações provenientes do seu banco de dados oriundos das dispensação de medicamentos, através do seu sistema de gestor que captura os dados de vendas farmácias privadas, aos beneficiários dos seus clientes, que são, aproximadamente, 17 milhões de beneficiários distribuídos em todo o território nacional.

\section{Hipertensão Arterial}

Quando comparamos os princípios ativos contemplados no Programa Aqui tem Farmácia Po-

\section{Figura 8 - Hipertensão Arterial: Comparação dos princípios ativos}
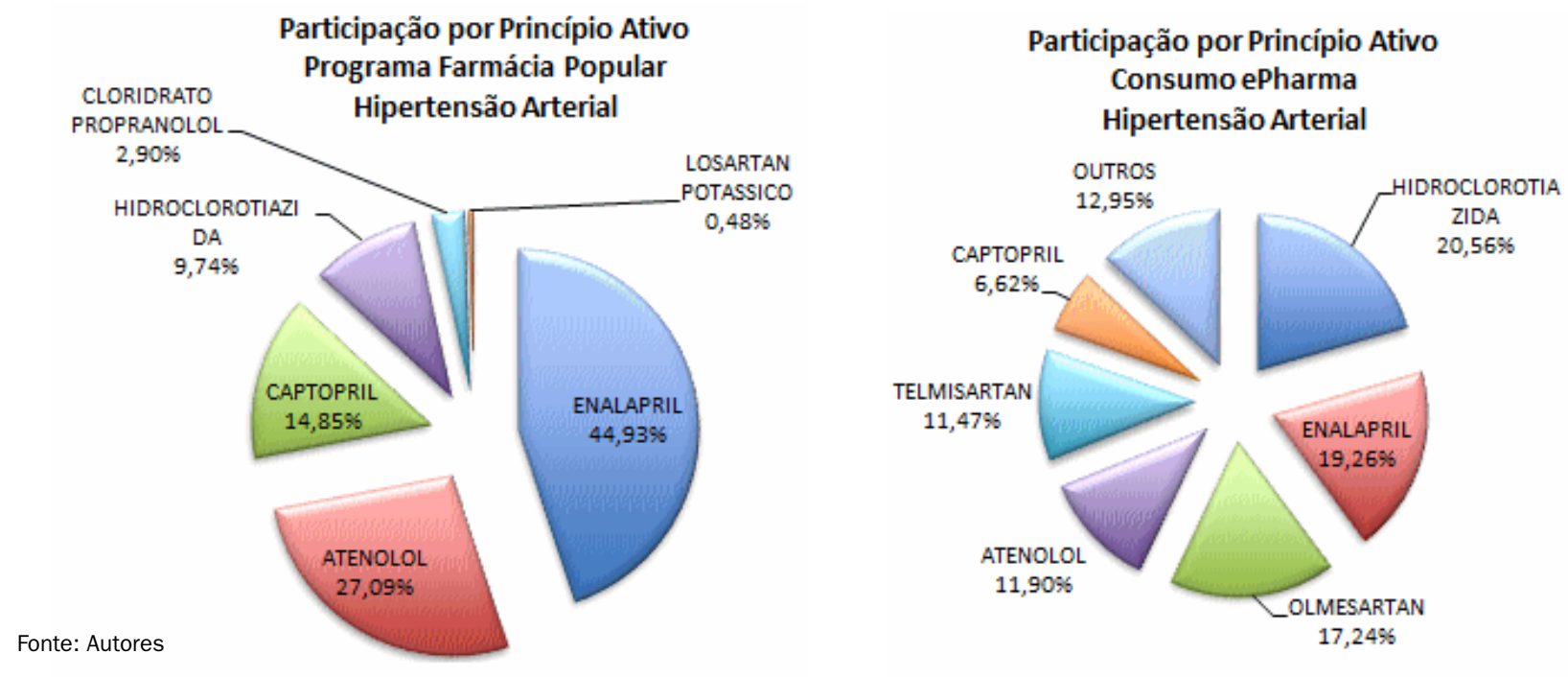
pular, para o tratamento de Hipertensão Arterial, com os princípios ativos mais consumidos no mercado brasileiro, segundo os dados de consumo dos programas de medicamentos gerenciados pela ePharma, verificamos que pelo menos, $29 \%$ dos mesmos não fazem parte do Programa Aqui tem Farmácia Popular, ou seja, Olmisartan e Telmisartan são componentes relevantes no mercado, de grande prescrição pela classe médica e não estão disponíveis e subsidiados pelo Programa do Estado (Figura 8).

$\mathrm{Na}$ análise dos 15 medicamentos mais consumidos entre o Programa FP e o consumo ePharma podemos verificar na Tabela 1 que no caso do Programa FP não há nenhum produto de referência entre os mais utilizados, o que já ocorre inversamente proporcional no segundo quadro, onde a utilização dos produtos de referência chega a $41,25 \%$. No consumo de medicamentos analisados no segmento privado, além de notarmos que os 3 primeiros produtos e princípios ativos, utilizados no tratamento de hipertensão arterial, não estão incluídos no programa público a utilização dos produtos genéricos é de $23,11 \%$ contra $57,05 \%$ no Programa. Podemos ainda verificar, na análise dos medicamentos mais consumidos, que no caso dos medicamentos utilizados no tratamento da Hipertensão, mais de 50\% destes não

Tabela 1 - Hipertensão Arterial: Comparação dos medicamentos

\begin{tabular}{|lccc|}
\hline \multicolumn{4}{c}{ FARMÁCIA POPULAR - HIPERTENSÃO ARTERIAL } \\
\hline PRODUTO & $\%$ PARTICIPAÇÃ0 & CLASSIFICAÇÃO & Princípio Ativo \\
\hline MALEATO ENALAPRIL (GENERICO) EMS & $14,74 \%$ & Genérico & Enalapril \\
\hline ATENOLOL (GENERICO) EMS & $9,56 \%$ & Genérico & Atenolol \\
\hline ENALABAL & $7,85 \%$ & Similar & Enalapril \\
\hline ATENOLOL (GENERICO) MEDLEY & $7,39 \%$ & Genérico & Atenolol \\
\hline CAPTOPRIL (GENERICO) EMS & $6,77 \%$ & Genérico & Captopril \\
\hline HIDROCLOROTIAZIDA (GENERICO) EMS & $5,62 \%$ & Genérico & Hidroclorotiazida \\
\hline MALEATO ENALAPRIL (GENERICO) MEDLEY & $5,30 \%$ & Genérico & Enalapril \\
\hline MALEATO ENALAPRIL (GENERICO) TEUTO & $4,48 \%$ & Genérico & Enalapril \\
\hline ATENOBAL & $3,94 \%$ & Similar & Atenolol \\
\hline CAPTOPRIL (GENERICO) MEDLEY & $3,19 \%$ & Genérico & Captopril \\
\hline VASOPRIL & $2,28 \%$ & Similar & Enalapril \\
\hline PRESSOTEC & $2,03 \%$ & Similar & Enalapril \\
\hline ANGIOPRIL & $1,65 \%$ & Similar & Enalapril \\
\hline ABLOK & $1,59 \%$ & Similar & Atenolol \\
\hline GLIOTEN & $1,55 \%$ & Similar & Enalapril \\
\hline Total & $77,94 \%$ & & \\
\hline
\end{tabular}

\begin{tabular}{|c|c|c|c|}
\hline \multicolumn{4}{|c|}{ CONSUMO EPHARMA - HIPERTENSÃO ARTERIAL } \\
\hline PRODUTO & $\%$ PARTICIPAÇÃOO & CLASSIFICAÇÃO & PRINCÍPIO ATIVO \\
\hline MICARDIS HCT & $13,38 \%$ & Referência & Telmisartan \\
\hline BENICAR HCT & $10,69 \%$ & Referência & Olmesartan+Hidroclorotiazida \\
\hline BENICAR ANLO & $7,48 \%$ & Referência & Olmesartan+Enalarpil \\
\hline MALEATO ENALAPRIL (GENERICO) EMS & $6,24 \%$ & Genérico & Enalapril \\
\hline BENICAR & $4,92 \%$ & Referência & Olmesartan \\
\hline MICARDIS & $4,78 \%$ & Referência & Telmisartan+Hidroclorotiazida \\
\hline ATENOLOL (GENERICO) EMS & $4,06 \%$ & Genérico & Atenolol \\
\hline OLMETEC HCT & $4,03 \%$ & Similar & Olmesartan+Hidroclorotiazida \\
\hline ENALABAL & $3,31 \%$ & Similar & Enalapril \\
\hline ATENOLOL (GENERICO) MEDLEY & $3,28 \%$ & Genérico & Atenolol \\
\hline ATACAND HCT & $3,22 \%$ & Similar & Candesartan+Hidroclorotiazida \\
\hline CAPTOPRIL (GENERICO) EMS & $2,88 \%$ & Genérico & Captopril \\
\hline HIDROCLOROTIAZIDA (GENERICO) EMS & $2,40 \%$ & Genérico & Hidroclorotiazida \\
\hline MALEATO ENALAPRIL (GENERICO) MEDLEY & $2,34 \%$ & Genérico & Enalapril \\
\hline MALEATO ENALAPRIL (GENERICO) TEUTO & $1,90 \%$ & Genérico & Enalapril \\
\hline & $74,91 \%$ & & \\
\hline
\end{tabular}

Fonte: Autores

estão disponíveis no Programa Aqui tem Farmácia Popular.

\section{Diabetes}

A exemplo dos fatos na hipertensão arterial, o mesmo ocorre quando comparamos os princípios ativos disponibilizados para o tratamento de Diabetes, mas em um porcentual menor. Aproxima-

damente $18 \%$ do consumo privado de medicamentos não fazem parte do Programa do Estado (Figura 9).

No tratamento para Diabetes, os dados demonstram que no consumo ePharma há uma relevante participação dos produtos genéricos (44\%) diferente do tratamento para Hipertensão, mas ainda assim há bastante divergência quando 


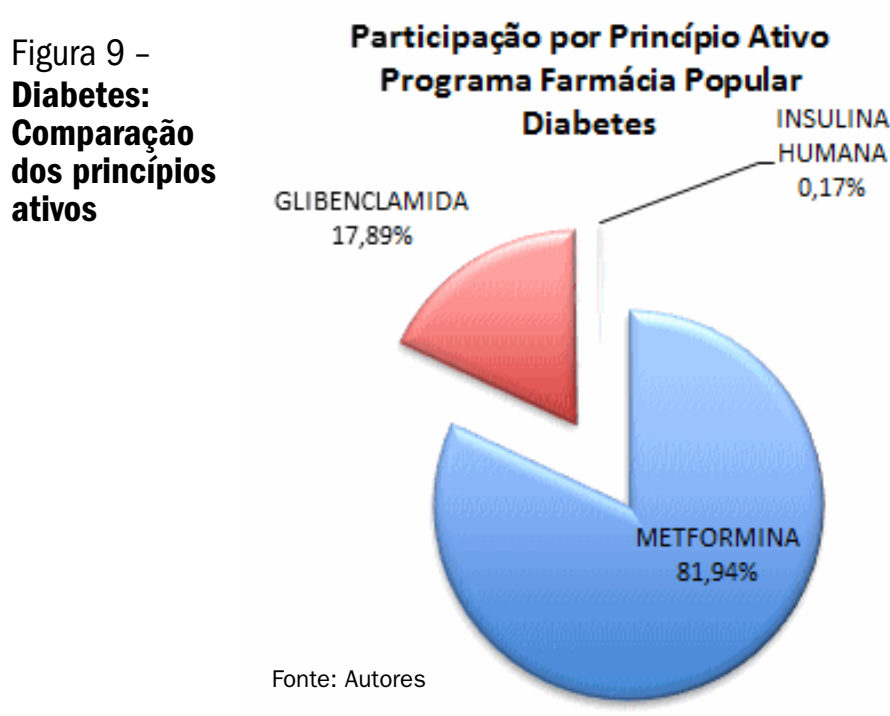

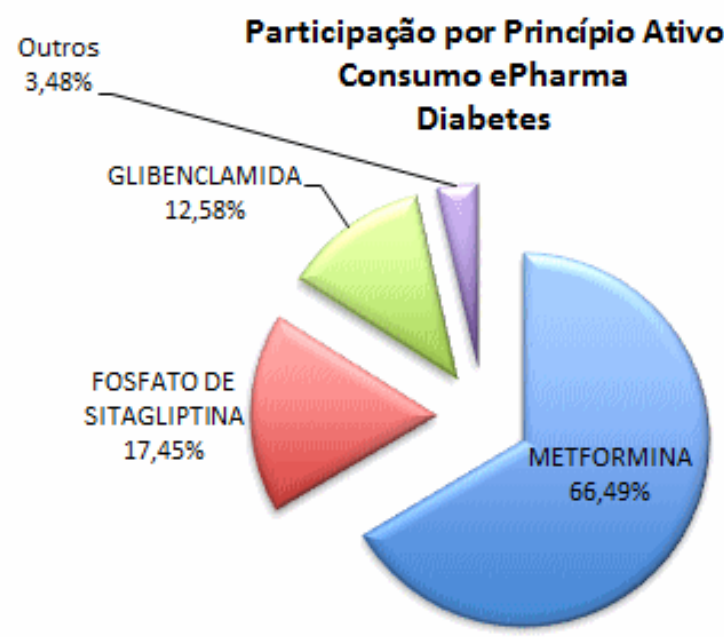

\section{Dislipidemia}

Já no caso do tratamento para Dislipidemia foi contemplado no Programa público apenas o princípio ativo Sinvastatina; o mesmo possui quase 50\% do consumo averiguado pela ePharma, mas há ainda outra metade onde são prescritos outros tipos de tratamento. $21,35 \%$ dos pacientes consomem produtos com Ezetimibe e 21,09\% com Atorvastatina (Figura 10).

\section{Tabela 2 - Diabetes: Comparação dos medicamentos}

\begin{tabular}{|c|c|c|c|}
\hline \multicolumn{4}{|c|}{ FARMÁCIA POPULAR - DIABETES } \\
\hline Produto & \% Participação & Classificação & Princípio Ativo \\
\hline GLIFAGE & $24,82 \%$ & Referência & Metformina \\
\hline CLORIDRATO METFORMINA (GENERICO) EMS & $24,03 \%$ & Genérico & Metformina \\
\hline CLORIDRATO METFORMINA (GENERICO) MEDLEY & $19,89 \%$ & Genérico & Metformina \\
\hline GLIBENCLAMIDA (GENERICO) EMS & $10,70 \%$ & Genérico & Glibenclamida \\
\hline CLORIDRATO METFORMINA (GENERICO) MERCK & $6,63 \%$ & Genérico & Metformina \\
\hline DAONIL & $2,43 \%$ & Referência & Glibenclamida \\
\hline GLIBENCLAMIDA (GENERICO) BIOSINTETICA & $1,23 \%$ & Genérico & Glibenclamida \\
\hline GLIONIL CP & $1,02 \%$ & Similar & Glibenclamida \\
\hline METFORMED & $0,89 \%$ & Similar & Metformina \\
\hline GLICEFOR & $0,81 \%$ & Similar & Glibenclamida \\
\hline METTA SR & $0,74 \%$ & Similar & Metformina \\
\hline GLICONIL & $0,73 \%$ & Similar & Glibenclamida \\
\hline GLIBENCLAZIDA & $0,68 \%$ & Similar & Glibenclamida \\
\hline FORMYN & $0,65 \%$ & Similar & Metformina \\
\hline CLORIDRATO METFORMINA (GENERICO) PRATI, DONADUZZI & $0,55 \%$ & Genérico & Metformina \\
\hline & $95,79 \%$ & & \\
\hline
\end{tabular}

\begin{tabular}{|lccc}
\hline \multicolumn{4}{c}{ CONSUMO EPHARMA - DIABETES } \\
\hline \\
\hline Produto & Participação & Classificação & Princípio Ativo \\
\hline GLIFAGE & $18,06 \%$ & Referência & Metformina \\
\hline JANUMET & $16,66 \%$ & Referência & Sitagliptina+Metformina \\
\hline CLORIDRATO METFORMINA (GENERICO) EMS & $16,42 \%$ & Genérico & Metformina \\
\hline CLORIDRATO METFORMINA (GENERICO) MEDLEY & $14,11 \%$ & Genérico & Metformina \\
\hline JANUVIA & $9,11 \%$ & Referência & Sitagliptina \\
\hline GLIBENCLAMIDA (GENERICO) EMS & $7,30 \%$ & Genérico & Glibenclamida \\
\hline CLORIDRATO METFORMINA (GENERICO) MERCK & $4,52 \%$ & Genérico & Metformina \\
\hline DAONIL & $1,73 \%$ & Referência & Glibenclamida \\
\hline GLIBENCLAMIDA (GENERICO) BIOSINTETICA & $0,83 \%$ & Genérico & Glibenclamida \\
\hline GLIONIL CP & $0,69 \%$ & Similar & Glibenclamida \\
\hline MEIFORMED & $0,61 \%$ & Similar & Metformina \\
\hline GLICEFOR & $0,55 \%$ & Similar & Glibenclamida \\
\hline GLUCOVANCE & $0,53 \%$ & Similar & Glibenclamida+Metformina \\
\hline LANTUS & $0,53 \%$ & Genérico & Insulina \\
\hline METTA SR & $0,52 \%$ & Similar & Metformina \\
\hline & $92,18 \%$ & & \\
\hline & & & \\
\hline
\end{tabular}

Fonte: Autores 
Figura 10 -

\section{Dislipidemia:}

Comparação dos princípios ativos

\section{Participação por Princípio Ativo Consumo ePharma Dislipidemia}

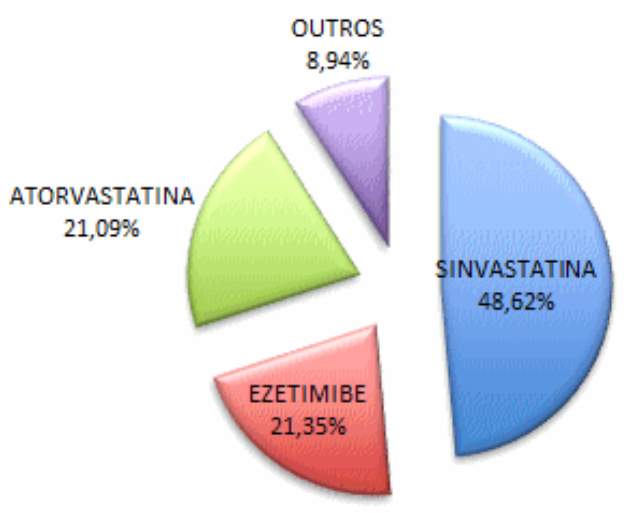

Fonte: Autores

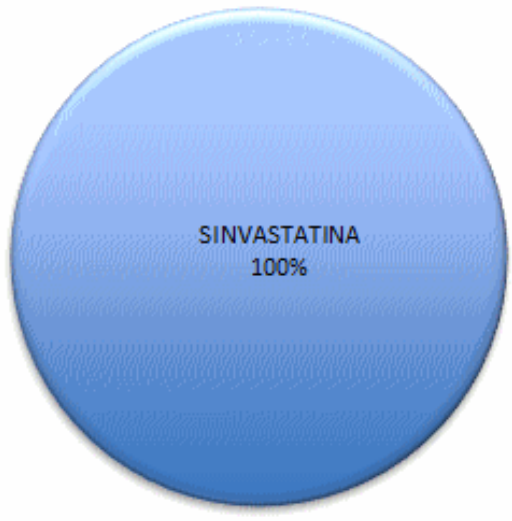

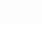

Conforme já descrito, no caso de dislipidemia, o governo apenas liberou a utilização de um princípio ativo dentro do programa. Neste caso, houve dispensação de $87 \%$ de medicamentos similares e de $13 \%$ de medicamentos genéricos. No consumo privado temos um porcentual de mais de $70 \%$ em medicamentos, para este tratamento,

\section{Tabela 3 - Dislipidemia: Comparação dos medicamentos}

que não são disponíveis no Programa (Tabela 3).

\section{Contraceptivos}

Quando comparamos os princípios ativos utilizados na contracepção não há tanta relevância entre os disponíveis no Programa Aqui tem Farmácia Popular e os consumidos no mercado privado. Nes-

\begin{tabular}{|lccc|}
\hline \multicolumn{4}{c}{ FARMÁCIA POPULAR - DISLIPIDEMIA } \\
\hline Produto & $\%$ Participação & Classificação & Princípio Ativo \\
\hline SINVASCOR & $49,50 \%$ & Similar & Sinvastatina \\
\hline CLINFAR & $12,91 \%$ & Similar & Sinvastatina \\
\hline SINVASTATINA (GENERICO) MEDLEY & $11,64 \%$ & Genérico & Sinvastatina \\
\hline SINVALIP & $11,10 \%$ & Similar & Sinvastatina \\
\hline SINVASTACOR & $5,21 \%$ & Similar & Sinvastatina \\
\hline VASLIP & $4,09 \%$ & Similar & Sinvastatina \\
\hline MENOCOL & $1,35 \%$ & Similar & Sinvastatina \\
\hline SINVASTATINA (GENERICO) SANDOZ & $1,23 \%$ & Genérico & Sinvastatina \\
\hline SINVASTAMED & $0,94 \%$ & Similar & Sinvastatina \\
\hline SINVASMAX & $0,60 \%$ & Similar & Sinvastatina \\
\hline SINVASTATINA (GENERICO) EMS & $0,30 \%$ & Genérico & Sinvastatina \\
\hline SINVATROX & $0,26 \%$ & Similar & Sinvastatina \\
\hline SINVASTON & $0,24 \%$ & Similar & Sinvastatina \\
\hline SINVAX & $0,23 \%$ & Similar & Sinvastatina \\
\hline CORDIRON & $0,12 \%$ & Similar & Sinvastatina \\
\hline & $99,70 \%$ & & \\
\hline
\end{tabular}

\begin{tabular}{|lccc}
\hline \multicolumn{4}{c}{ CONSUMO EPHARMA - DISLIPIDEMIA } \\
\hline Produto & \% Participação & Classificação & Princípio Ativo \\
\hline UYTORIN & $38,92 \%$ & Referência & Atorvastatina \\
\hline LIPITOR & $19,89 \%$ & Referência & Ezetimiba +Sinvastatina \\
\hline SINVASCOR & $12,63 \%$ & Similar & Sinvastatina \\
\hline CRESTOR & $7,33 \%$ & Referência & Rosuvastaina \\
\hline SINVASTATINA (GENERICO) MEDLEY & $4,23 \%$ & Genérico & Sinvastatina \\
\hline CLINFAR & $3,47 \%$ & Similar & Sinvastatina \\
\hline SINVALIP & $2,92 \%$ & Similar & Sinvastatina \\
\hline ZETSIM & $2,59 \%$ & Similar & Ezetimiba +Sinvastatina \\
\hline SINVASTACOR & $1,45 \%$ & Similar & Sinvastatina \\
\hline CITALOR & $1,19 \%$ & Referência & Atorvastatina \\
\hline VASLIP & $1,11 \%$ & Similar & Sinvastatina \\
\hline SINVASTATINA (GENERICO) EMS & $0,43 \%$ & Genérico & Sinvastatina \\
\hline ZETIA & $0,42 \%$ & Similar & Ezetimiba \\
\hline MENOCOL & $0,35 \%$ & Similar & Sinvastatina \\
\hline SINVASTATINA (GENERICO) SANDOZ & $0,33 \%$ & Genérico & Sinvastatina \\
\hline & $97,27 \%$ & & \\
\hline
\end{tabular}


MARCOS INOCENCIO E BRUNA DE VIVO

Figura 11 - Contraceptivos: Comparação dos princípios ativos

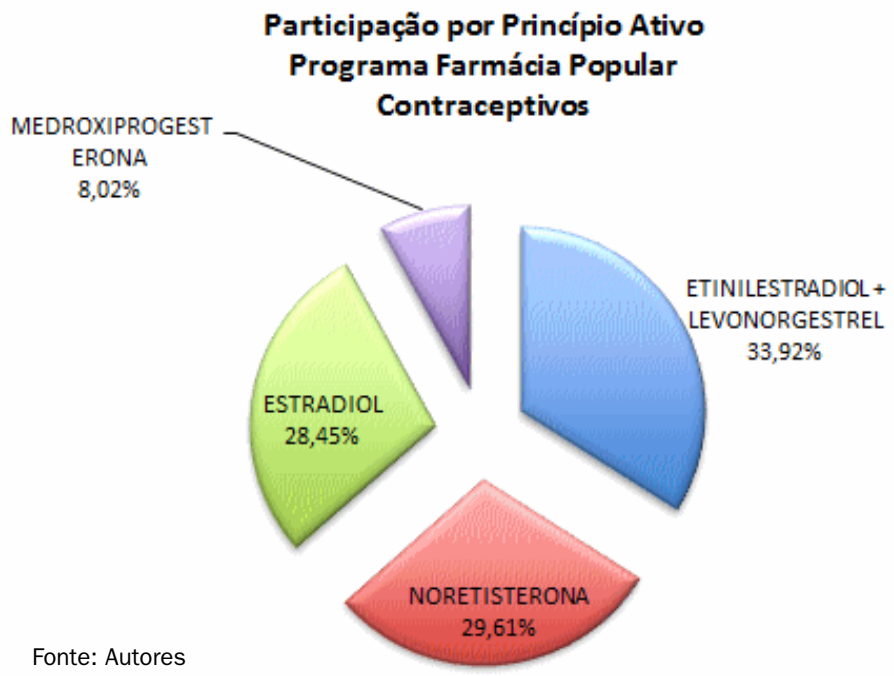

tes casos, haverá sim divergência quando tratamos dos produtos (marcas registradas), pois especificamente no caso de anticoncepcionais há bastante diferença nas dosagens dos produtos (Figura 11).

Quando comparamos os produtos na contracepção a diferença fica entre a utilização de medicamentos mais novos como Yasmin e Yaz, onde

Tabela 4 - Contraceptivos: Comparação dos medicamentos

\begin{tabular}{|c|c|c|c|}
\hline \multicolumn{4}{|c|}{ FARMÁCIA POPULAR - CONTRACEPTIVOS } \\
\hline Produto & \% Participação & Classificação & Princípio Ativo \\
\hline MICROVLAR & $27,32 \%$ & Similar & Etinilestradiol+Levonorgestrel \\
\hline MESIGYNA & $25,17 \%$ & Referência & Noretisterona+Estradiol \\
\hline NORDETTE & $10,02 \%$ & Referência & Etinilestradiol+Levonorgestrel \\
\hline DEPO PROVERA & $8,13 \%$ & Referência & Medroxiprogesterona \\
\hline CICLO 21 & $8,13 \%$ & Referência & Etinilestradiol+Levonorgestrel \\
\hline $\begin{array}{l}\text { ENANTATO NORETISTERONA+VALERATO } \\
\text { ESTRADIOL (GENERICO) EUR }\end{array}$ & $7,56 \%$ & Genérico & Noretisterona+Estradiol \\
\hline NOREGYNA & $6,95 \%$ & Similar & Noretisterona+Estradiol \\
\hline CONTRACEP & $3,07 \%$ & Similar & Medroxiprogesterona \\
\hline NOCICLIN & $1,34 \%$ & Similar & Etinilestradiol+Levonorgestrel \\
\hline MICRONOR & $1,19 \%$ & Referência & Noretisterona \\
\hline NORESTIN & $0,43 \%$ & Similar & Noretisterona \\
\hline GESTRELAN & $0,33 \%$ & Referência & Etinilestradiol+Levonorgestrel \\
\hline CICLOFEMME & $0,24 \%$ & Similar & Etinilestradiol+Levonorgestrel \\
\hline $\begin{array}{l}\text { ENANTATO NOREIISTERONA+VALERATO } \\
\text { ESTRADIOL (GENERICO) CIFARMA }\end{array}$ & $0,07 \%$ & Genérico & Noretisterona+Estradiol \\
\hline CONCEPNOR & $0,03 \%$ & Similar & Etinilestradiol+Levonorgestrel \\
\hline & $100,00 \%$ & & \\
\hline
\end{tabular}

\begin{tabular}{|c|c|c|c|}
\hline \multicolumn{4}{|c|}{ CONSUMO EPHARMA - CONTRACEPTIVOS } \\
\hline Produto & \% Participação & Classificação & Princípio Ativo \\
\hline MICROVLAR & $18,05 \%$ & Similar & Etinilestradiol+Levonorgestrel \\
\hline MESIGYNA & $16,38 \%$ & Referência & Noretisterona+Estradiol \\
\hline NORDETTE & $6,58 \%$ & Referência & Etinilestradiol+Levonorgestrel \\
\hline CICLO 21 & $5,75 \%$ & Referência & Noretisterona+Estradiol \\
\hline $\begin{array}{l}\text { ENANTATO NORETISTERONA+VALERATO } \\
\text { ESTRADIOL (GENERICO) EUR }\end{array}$ & $4,78 \%$ & Genérico & Noretisterona+Estradiol \\
\hline NOREGYNA & $4,35 \%$ & Similar & Noretisterona+Estradiol \\
\hline DEPO PROVERA & $3,05 \%$ & Referência & Medroxiprogesterona \\
\hline DIANE 35 & $2,66 \%$ & Referência & Etinilestradiol+Ciproterona \\
\hline CERAZETTE & $2,35 \%$ & Referência & Desogestrel \\
\hline MERCILON & $2,34 \%$ & Referência & Desogestrel+Etinilestradiol \\
\hline ELANI & $2,05 \%$ & Similar & Drospirenona+Etinilestradiol \\
\hline YASMIN & $1,95 \%$ & Referência & Drospirenona+Etinilestradiol \\
\hline YAZ & $1,84 \%$ & Referência & Drospirenona+Etinilestradiol \\
\hline BELARA & $1,82 \%$ & Referência & Clomadinona+Etinilestradiol \\
\hline TAMISA & $1,44 \%$ & Similar & Etinilestradiol+Gestodeno \\
\hline & $75,38 \%$ & & \\
\hline
\end{tabular}

\section{Participação por Princípio Ativo}

Consumo ePharma

Contraceptivos

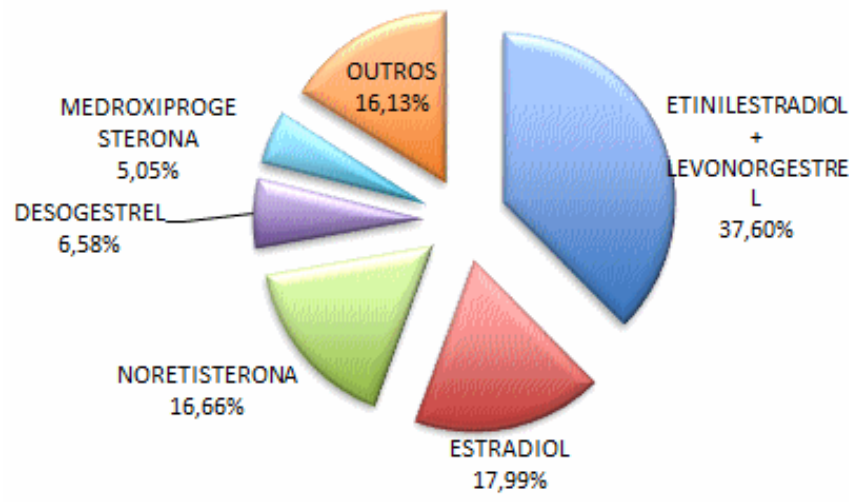

a dosagem de hormônios é menor em relação às pílulas mais antigas (Tabela 4). Nos casos dos contraceptivos, apenas aproximadamente 11\% dos princípios ativos, consumidos nos programas privados, não estão contemplados no programa do governo.

Fonte: Autores 


\section{CONCLUSOES E CONSIDERAÇÕES FINAIS}

No Brasil, há milhões de pessoas sem acesso aos medicamentos. Segundo o Ministério da Saúde (2003), do ponto de vista do indivíduo, esse quadro repercute em agravamento de enfermidades, perda de qualidade de vida, incapacidade para o trabalho e sofrimento individual e familiar. Para o sistema de saúde, diminui a efetividade do atendimento prestado, reduz a capacidade de atendimento, exige a organização de serviços mais complexos e acarreta um considerável aumento dos gastos.

Os medicamentos têm apresentado papel relevante na redução das taxas de mortalidade e morbidade da população em diversos países, principalmente naqueles em que o acesso a esses insumos é uma realidade. Ademais, o acesso aos medicamentos é um componente essencial de inclusão social e de busca da equidade e fortalecimento do sistema de saúde. Salienta-se, ainda, que o acesso aos medicamentos não pode estar desvinculado da existência de uma rede de serviços de saúde, em particular de uma estrutura de assistência farmacêutica pública e privada e de uma relação equilibrada com o mercado, que possibilite a aquisição de medicamentos pelas famílias.

Em face deste contexto, o Programa Farmácia Popular, que foi constituído para atender à demanda da população quanto ao acesso aos medicamentos prescritos, para a redução de gastos públicos com saúde e ainda para contribuir para melhora da saúde pública, atende parcialmente tais questões.

O Programa pode ser considerado eficaz dentro da sua abrangência, porém ainda possui limitações em seu escopo de atuação. A estratégia do governo de ação organizada em rede através de parceria público-privada para o credenciamento ao Programa de farmácias e drogarias privadas contribuiu de forma significativa para a expansão deste, já que por meio desta rede foi possível alcançar 14.005 pontos de dispensação presentes em 2.467 municípios espalhados em todo o território nacional. Esta abrangência pode ser considerada bastante significativa se comparada com os pontos de dispensações públicos que compõem o Programa Farmácia Popular, que são 543 pontos distribuídos em 543 municípios. A expansão do Programa através de parceria estratégica para a inclusão de farmácias e drogarias privadas pode alcançar maior número de atendimentos a população, que passou a usufruir de mais pontos de dispensações, sendo que através delas o Estado atingiu em 2010, em números estimados, 22.515 mil unidades dispensadas para 552 mil beneficiários. Se os números, ainda inexpressivos, não mostram resolução da falta de acesso aos medicamentos prescritos, ao menos mostram um maior contingente da população que passou a ser atendida, haja vista que os números do Programa através dos pontos próprios mantiveram a sua consistência de atendimento. Podemos destacar também que o Programa através da parceria com pontos de atendimento privados passou a suporta a população usuária da rede privada de saúde como uma alternativa.

O subsídio do Estado e a concentração das dispensações do Programa em medicamentos genéricos e de marcas similares favorece as pessoas de baixa renda ao acesso aos medicamentos e viabiliza a adesão ao tratamento desta população, já que passaram a ter acesso a medicamentos com preços mais acessíveis. Outro fator importante é que, considerando os preços mais acessíveis, o Programa Aqui tem Farmácia Popular pode contribuir para a diminuição dos gastos gerados pela compra de medicamentos e, também minimizar as despesas do Sistema Único de Saúde com internações que são provocadas pelo abandono do tratamento. 
Em relação ao rol de produtos que integram o Programa Aqui tem Farmácia Popular, há uma divergência significativa quando comparados aos medicamentos mais prescritos na rede privada e ainda a não inclusão de medicamentos destinados ao tratamento de algumas patologias crônicas, que atualmente concentram os grandes gastos da saúde pública. Para equacionar esta questão seria essencial a expansão do Programa no sentido de contemplar medicamentos de uso continuado destinados a $100 \%$ das patologias consideradas crônicas assim como considerar a inclusão dos medicamentos mais prescritos pela sistema de saúde.

Na verdade, o formato do Programa Aqui tem Farmácia Popular restringe o acesso universal aos medicamentos, ferindo, inclusive, o princípio da universalidade e do atendimento a saúde, trazendo transtornos a população mais carente desprovida de recursos financeiros e, que por esta razão, não tem poder de compra para iniciar e concluir seu tratamento, aumentando ainda mais a exclusão social.

De qualquer forma, o Programa Aqui tem Farmácia Popular é uma iniciativa do Estado em tomar a causa da falta de acesso da população aos medicamentos essenciais e liderar a força política necessária para remover os obstáculos existentes, encorajar a inovação necessária e mover essa situação de insustentabilidade a uma solução sustentável. A organização em rede através da parceria privada com farmácias e drogarias busca alcançar uma bem-sucedida transformação no sistema de saúde, onde os atores envolvidos tomam como base suas decisões sobre saúde em uma definição comum de valor, para uma promoção da dispensação de medicamentos a população, mais eficaz.

\section{REFERÊNCIAS}

AGRANOFF, R.; MCGUIRE, M. (2001). After the network is formed: process, power and performance. In: M. P. Mandell,
Getting results through collaboration: network and network structures for public policy and management. Westport: Quorum.

BRASIL. (2001). Ministério da Saúde. (P. n. medicamentos, Ed.) Acesso em 22 de Fev de 2011, disponível em Secretaria das Políticas de Saúde: http://bvsms.saude.gov.br/bvs/publicacoes/ politica_medicamentos.pdf

BRASIL. (2010). Sala de Situação em Saúde. (MINISTERIO DA SAÚDE) Acesso em 4 de Abril de 2011, disponível em http://189.28.128.178/sage/

CASTELLS, M. (2007). A sociedade em rede (10 ed ed.). São paulo: Editora Paz e Terra.

CDCP. (2003). The power of prevention: reducing the health and economic burden of chronic disease. Center for Disease Control and Prevention, Department of Health and Human Services.

COHEN, J. E. (2005). Human population grows up. Scientific American, 293, pp. 48-55.

DABAS, E N. (1995). De la desestructuration de lo macro a la estructuración de lo micro: las redes sociales en la reconstrucción de la sociedad civil. Buenos Aires: Paidós.

FLEURY, S., \& OUVERNEY, A. M. (2007). Gestão de redes: a estrategia de regionalização da política de saúde. Rio de Janeiro: FGV.

IBGE. (2009). Ministério do Planejamento, Orçamento e Gestão. Acesso em 18 de Nov de 2009, disponível em http://www. ibge.gov.br/home/presidencia/noticia_visualiza.php?id_ noticia $=1445$ \&id_pagina $=1$

INOJOSA, R. M. (1998). Redes e redes sociais: versão preliminar. FUNDAP.

INTERFARMA. (2010). Acesso e financiamento à saúde no Brasil. Associação da indústria Farmacêutica de Pesquisa, São Paulo.

JUNQUEIRA, L. A. (2000). Intersetorialidade, transsetorialidade e rede sociais na saúde. RAP, 34 (6), pp. 35-45.

KEAST, R., MANDELL, M., BROWN, K., e WOOLCOCK, G. (2004). Network structures: working differently and changing expectations. Public Administration Review , 64 (64), pp. 363-372.

NAJMANOVICH, D. (1995). El lenguaje de los vínculos: de la independencia absoluta a la autonomia relativa. In: E. Dabas, Redes: el lenguaje de los vínculos (p. 33-76). Buenos Aires: Paidós.

OECD. (2009). Orgnisation for Economic Co-Operation and Development. Acesso em 21 de Out de 2009, disponível em http// www.oecd.org

ONU. (2005). Prevent chronic disease: a vital investment. Organização das Nações Unidas, World health Organisation, Genegra. 
ARTIGOS ACESSO A MEDICAMENTOS: ANÁLISE DAS ESTRATÉGIAS DO ESTADO PARA O DESENVOLVIMENTO DO PROGRAMA FARMÁCIA POPULAR

OPAS. (2007). Saúde nas Americas. Organização Pan-Americana de Saúde. Publicação Científica e Técnica No. 622.

O’TOOLE, L. J. (1997). Treating networks seriously: pratical and research-based agendas in public administration. Public Administration Review, v. 57, p. 45-53.

PROGENERICOS. (2010). Evolução do Mercado de Genéricos no Brasil. Acesso em 4 de Abril de 2011, disponível em http://www. progenericos.org.br/infomercado2010.shtml

SAIDÓN, O. (1995). Las redes: pensar de outro modo. In: E. N. DABAS, Redes: el lenguaje de los vínculos (pp. 203 - 214). Buenos Aires: Paidós.
SOUZ, Q., QUANDT, C. (2008). Metodologia de análise de redes sociais. In: F. Duarte, C. Quandt, \& Q. Souza. O tempo das redes (p. 31-63). São Paulo: Perspectiva.

SOUZA, C. M. (2005). Perspectivas teóricas para o estudo das redes de cooperação interempresariais. In: F. Teixeira, Gestão de redes de cooperação interempresariais (pp. 41-57). Salvador: Casa da Qualidade.

TOURAINE, A. (1959). Enterprise et bureaucratie (1 ed ed.). Sociologie du Travail. 